\title{
Co-design: Tactile Models and Prototype as Common Language Tools between Designers and Visually Impaired People
}

\author{
Andréa Quadrado Mussi", Luísa Batista de Oliveira Silva, Luísa Fernanda Nercolino Deon, \\ Thaísa Leal da Silva, Lauro André Ribeiro
}

Postgraduate Program in Architecture and Urbanism, IMED Faculty, Passo Fundo, 990101030, Rio Grande do Sul, Brazil

Received March 2, 2021; Revised July 20, 2021; Accepted August 22, 2021

\section{Cite This Paper in the following Citation Styles}

(a): [1] Andréa Quadrado Mussi, Luísa Batista de Oliveira Silva, Luísa Fernanda Nercolino Deon, Thaísa Leal da Silva, Lauro André Ribeiro , "Co-design: Tactile Models and Prototype as Common Language Tools between Designers and Visually Impaired People," Civil Engineering and Architecture, Vol. 9, No. 5, pp. 1627-1639, 2021. DOI: 10.13189/cea.2021.090532.

(b): Andréa Quadrado Mussi, Luisa Batista de Oliveira Silva, Luísa Fernanda Nercolino Deon. Thaísa Leal da Silva, Lauro André Ribeiro (2021). Co-design: Tactile Models and Prototype as Common Language Tools between Designers and Visually Impaired People. Civil Engineering and Architecture, 9(5), 1627-1639. DOI: 10.13189/cea.2021.090532.

Copyright $\mathrm{C} 2021$ by authors, all rights reserved. Authors agree that this article remains permanently open access under the terms of the Creative Commons Attribution License 4.0 International License

\begin{abstract}
This article presents the use of tactile models and prototype as common language tools among designers, blind and visually impaired (B\&VI), inserted in a collaborative design methodology. With the objective of realizing an interior architecture project and an outdoor area, including toys, for an association for visually impaired people in the city of Passo Fundo, RS, Brazil. It describes the process of participation and interaction between Association members, both adults and children, and architects in the development of these projects. It shows results of two co-design actions, which will subsidize a broader objective of a research that aims to define co-design methods, techniques and tools applied to the inclusion of Visually Impaired People in the process of architecture, urbanism, landscaping and interior design. The research related two co-design. The first is the co-design of the waiting / reception room and the external area for socializing and leisure, carried out with the adults of the association, took place in three moments: in the focus group, in the interaction with the tactile model and on the tours accompanied. The second co-design was carried out with the children of the association to develop two toys, the first to be inserted within the proposal of improving reception/ waiting, and the second for placement in the outdoor area of socializing and leisure. The interaction among designers, blind and visually impaired was
\end{abstract}

intensive, allowing modifications and diverse insights about types of floors, layout and better and adequate colors for the best comfort and mobility inside the spaces. It seeks to demonstrate the importance of co-design as a way of including B\&VI, as they are able to increase well-being and self-esteem, while effectively participating in the creation of the environment in which they are inserted; they manage to leave the passive zone that they normally find themselves in with regard to the architectural design process. The next steps of the research are to finalize the toy design of the external area and the execution of all spaces.

Keywords Collaborative Project, Blind and Visually Impaired People, Design Process, Digital Fabrication

\section{Introduction}

In the year of 2011, World Health Organization (WHO), in partnership with the World Bank, produced the World Disability Report published under the original title "World Report on Disability", in which it was found that every 5 seconds a person becomes blind in the world and that, of the total blindness cases, $90 \%$ occur in underdeveloped 
countries. Around the world, people with disabilities have lower health prospects, lower levels of schooling, lower economic participation, and higher poverty rates compared to people without disabilities. In part, this is due to the fact that people with disabilities face barriers to access to services and infrastructure that for the rest of the population have long been considered guaranteed [1].

Concerning the participation of the B\&VI in architecture, Bianchini and Heylighen [2] affirm that the deficiency arises from interactions with the surrounding environment that are susceptible of structural and design interventions, and not inherently of levels of capacity, health status or associated degrees of disability. That is, the B\&VI have a great distance in regard to architecture and urbanism since it is, often, considered accessible spaces that only offer solutions for people with mobility difficulties. This situation is faced with the questioning of the authors: how can architects and urban planners be fair to all types of disabilities without prioritizing a problem arising from only one of them?

The present article has as objective to study the collaborative project, which is demonstrated as a great tool of the project process both in decision making, when it is focused on the B\&VI, and in the form of social inclusion of people who, due to the supremacy of vision in architecture, always remain in passive zones, without any collaboration with the environment in which they are inserted. And it has as objective, however, to elaborate a proposal of project of improvement of an internal environment and of an external area of coexistence. However, due to the degree of importance that the toys to be elaborated for the children in the two mentioned spaces have, the collaborative project will be divided in two parts: a collaborative project with the adults and a collaborative project with the children.

\section{Collaborative Projects with B\&VI: The Methodology Used and Its Results}

Present the research design, research type, research Alexander et al. [3] point out how participation is felt by users as a pleasant sensation in itself, because human nature makes people have the intrinsic need to create and control. Therefore, when they feel able to manage the space where they live or work it is created an idea of territoriality and property necessary for people to really take ownership of the environment in which they are inserted.

According to Carneiro, Barros and Zibel [4], the participation of users in the design of a project allows in-depth discussions on the different needs for the environment. According to their daily activities delimits the possibilities of the project and so are made constant exchanges between the architects and users for the progress of the project and finally an appropriation of the environment by them. As well, they promote the strengthening of the collective with the projected environment [5].

Another term used for participatory or collaborative design is the co-design, which was researched by Caixeta and Fabrício [6] regarding the methods that involve it. Co-design is the project process that searchs to understand and learn from the user his / her expertise regarding the theme addressed in a particular project and context $[7,8,9]$, or still, defined as Experience-based Co-design [10]. Participation in meetings only would not be sufficient to achieve effective user participation, requiring additional techniques for wider user interference. The limitations are related to the user's understanding of representation, requiring more accurate and understandable representations both for the users themselves and for the architects to interact and produce conclusions about participation. One of the conclusions of the authors is that users are more useful in the process in the initial stages of the project, and subsequent steps require a more accurate technical knowledge, making the users themselves, little contribute to the evolution of the project. Besides that, users directly involved with the program routine of a specific project theme are more useful to the process than are occasional users [6]. Therefore, the associates themselves and those who frequent more the institution would be the most appropriate users and considering that there are spaces shared by both adults and children, both participated in the process.

For B\&VI the representation is crucial for the proper understanding of the project and its effective interaction with the designers. Participation is nothing more than a way of relating, generating a satisfaction in the users, because by helping to create the environment in which they live creates a feeling of rooting between them and the world in general around them, is as inclusive way for disability people [11]. The use of tactile plans and tactile models were the means to generate understanding and exchange between associates and designers. Tactile plans have already served as interface in previous collaborative projects [7,12] regarding the new headquarters of association for blind [7], this article being the continuity of the process, with the use of tactile model because it is an interior design.

The article is subdivided into two collaborative projects (Figure 1), carried out in concomitance, but by degree of importance should be presented separately. The collaborative project with adults will lead to the elaboration of a project proposal for the improvement of an internal space, the waiting room/reception, and also an outdoor area for socializing and leisure. However, the collaborative project with children has become necessary since, for the elaboration of toys for the use of children 
with visual impairment, it is important the approximation and knowledge of the reality in which they are inserted and how they behave. Proposals will be presented for toys both for the internal area and for the external area. In both collaborative projects occurred the Focus Group to obtain information that, according to Sperling, Vandier and Scheeren [13], happens from a contact with the space in study, to knowledge of the same, and later there is an interaction with the participants to understand wanted the needs. And in order for information to be transmitted effectively between the sender and receiver, one must rely on the diversity of information media.

Collaborative design is the main method used. Each methodological step involved co-design characteristics. There is interaction between designers and associates (adults and children) in the first, third and fifth stages, and in the sixth stage in the future; and between team members (composed of three designers) in the second and fourth stages. The steps are described as follows:

(i) First step - Focus group with adults and Focus group with children; Second stage - designers made a proposal for the waiting / reception space and external area, each area containing a toy;

Third stage - Collaborative Project - presentation of the proposal. The representation consisted of:

Tactile model of the waiting/reception;

Prototype (1:1) of the toy for outdoor area;

The internal waiting/reception toy was made exclusively based on the focus group with the children and responsible, as well as the external area was made based on the focus group with the adults, exclusively. While the reception/wait design and the toy for the outside area involved a wider interaction between associates and designers. The toy involved both a briefing with a low vision child (held at another time in graduation subject) and feedback from other children in the use of the prototype;

(iv) Fourth stage - Designers made adjustments to the reception/wait design. As for the toy of the external area, the adjustments are still in progress;

Fifth stage - Collaborative Project - Presentation of the reception/waiting projects and the external area for the adult associates;

(vi) Sixth stage - Collaborative Project - in progress, which would be the presentation of another prototype for children with the suggested modifications for interaction between designers and associated children.

In the next subsections, each step is explained, dividing collaborative projects into two groups of users: adults and children.

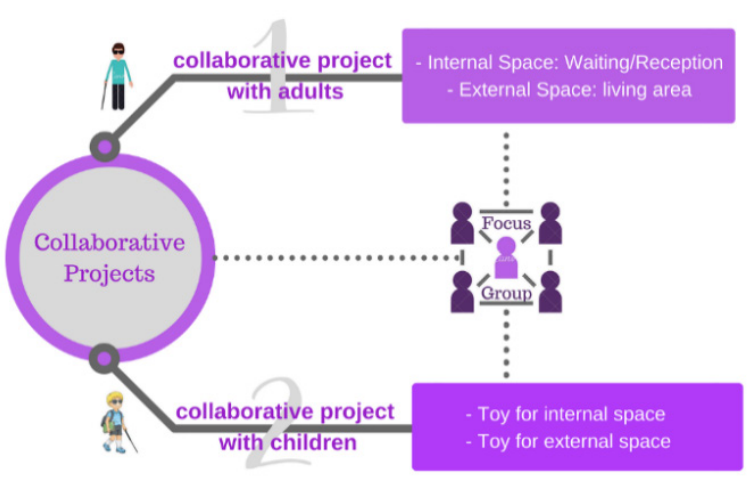

Figure 1. Division of collaborative projects

\section{Results and Discussions}

\subsection{Collaborative Project 1 - With Adult Association Members}

The first activity fulfilled to appropriate the needs and aspirations for the improvement of the waiting room/reception and for the external area and for the association's leisure was the Focus Group activity (Figure 2). The way Morgan [14] describes how the planning of a Focus Group should happen is, first of all, the importance of the nature of the data and its impact by which it is sought to achieve the objectives. The subsequent decision is about structuring the groups that will participate in the activity and their levels of involvement with the problem. Subsequently, the participants were defined as 7 participants in the 25-50 year age group divided as follows: 2 blind people, 1 of whom is a man and the other a woman - 4 are women with low vision and different degrees of visual acuity, being 1 man and 3 women - 1 collaborating participant of the association. The moderators, therefore, were the teacher of the discipline and her students.

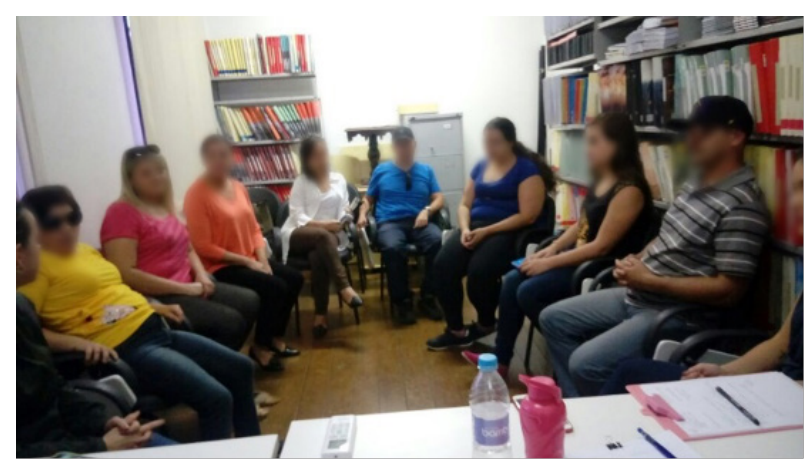

Figure 2. Focus group with adults

It is important to emphasize that moderators should lead guiding topics for the activity, so the main topics for the Focus Group for the waiting room were: "What is done in space? Functions. How many people use it? What is necessary? What aspects need to be improved? Floor, 
furniture and furniture organization?". For the area of socializing and leisure of the external area the following guiding topics were listed: "What is necessary for the external area to become inviting for members? What activities would you like to do in it? What physical elements need to be improved for safe use?".

The dynamics happened in the Association's activity of readings room structured through the guiding topics and as the conversation progressed occasioned what Morgan [14] defined as a moderate funnel structure, in which the general topics arise, questions becoming more and more specific. With this, the activity lasted 1 hour and was recorded for further analysis.

The first topics mentioned were directed to the waiting room, what their needs and main difficulties found for the effective use of space. Regarding the floor, the information transmitted was that the floor does not have any type of alert already in the access to the room and that for greater difficulty still has a step. Also, because the association is inserted in an old house ceded by the city hall, it has a floor with many irregularities. This first topic was challenging since, although the participants had a real knowledge of the space, it was necessary to question them about what measures would be most interesting to help new B\&VI that could come to know and need to use the space. This topic was of extreme importance for the elaboration of the proposal for the floor that will have differentiation of colors and textures. The second topic discussed the furniture in the room: are they cozy for the wait between an activity and another of the associates? Is the layout of today's furniture correct? What would be the main elements to make the room comfortable?

The questions of the furniture led to the third guiding topic that treated about the function of the room: what is the main activity performed by the members inside this space? How many people use it? How often? The participant 3 , blind from birth, was very unsatisfied with the lack of cosines of the room due to the lack of comfortable armchairs, lack of a place for the availability of water, coffee or other fast food since, often, you must wait more than 1 hour between the shifts of your activities. The participants mostly agreed with the affirmative, however, as expected there were issues unrelated to the starting topic, such as the nuisance felt by the noise coming from the street that disturbs reading classes. Such statements lead to the last guiding topic that treats about user satisfaction with the place that, according to the participants, does not have any kind of comfort and little space that accentuates the result of an erroneous disposition of the furniture. Thus, all the guiding topics (Figure 3) were discussed and taken to the evaluation and elaboration of the project proposal.

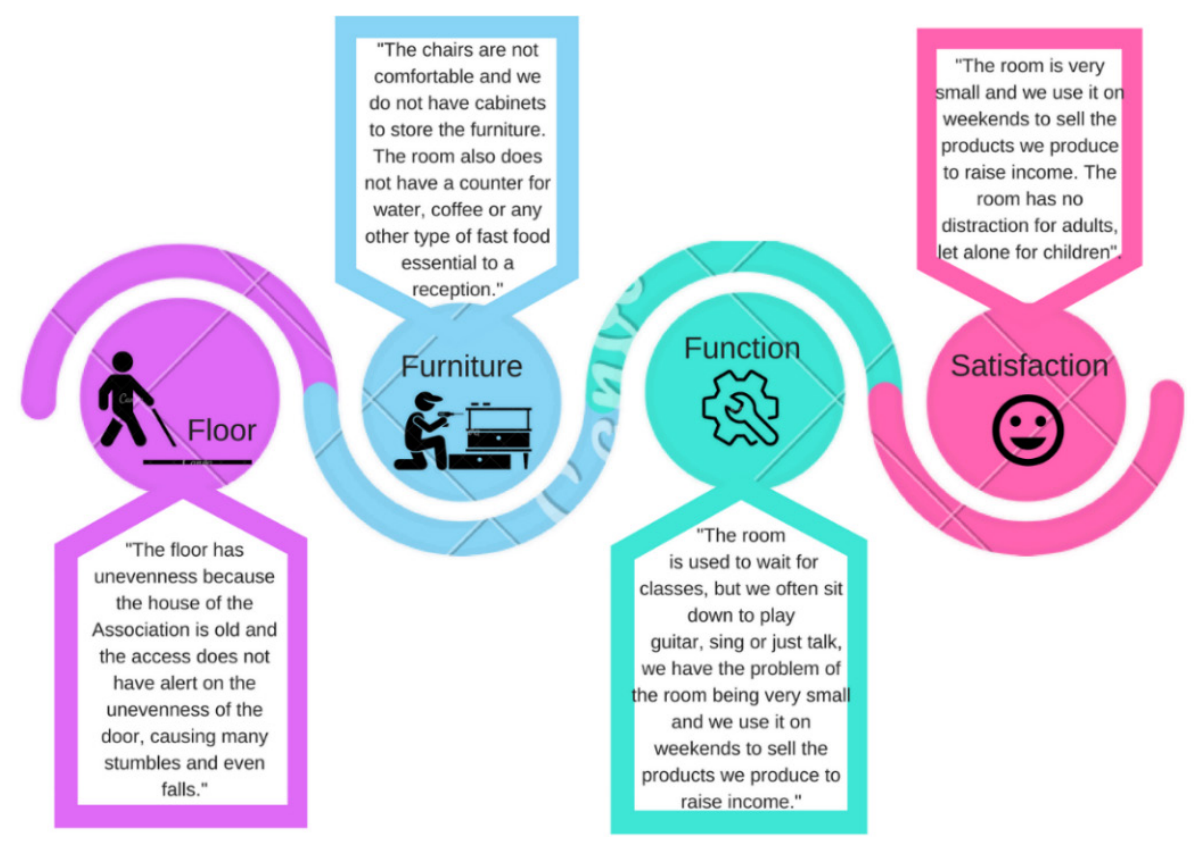

Figure 3. Guiding topics for the waiting/reception room and description of what the participants said about the topic 
The tactile model of the waiting room was elaborated in FabLab and for the solution of the floor (Figure 4) was elaborated a proposal of different textures and colors. It was also decided to place tactile floor alert only in the access to the room. For a better understanding of the project, the views will be presented separately, with due explanations.

In view 1 (Figure 5), a storage cabinet was developed for small utensils necessary for the sales activities of the association's products on weekends, with the same thickness of the toy located just below. The color for the wall is also the result of punctual choices that occurred during the Focus Group activity, in which participants were able to test and evaluate which colors would be most consistent to use without any confusion of information. The toy present in this design view is part of the collaborative project 2 .
In view 2 (Figure 6) there was a composition of colors for the wall, being elaborated a panel in blue-gray color for the placement of hooks, which will be used to hang bags with products sold during the weekends, as well as support to hang walking sticks on a daily basis. There was also the elaboration of a counter so that coffee, water and some fast food could be offered. This was one of the most recurring requests during the Focus Group as it will improve comfort for those who need to wait a long time on the spot. Everything has been planned so users know where the utensils are located on the countertop, such as a panel of cups that will be attached to the wall and also two dispensers of bullets. Puff's were also inserted to support the multifunctional activities of the room, such as when members gather to play guitar and sing. An air locker for diverse storage has also been developed.
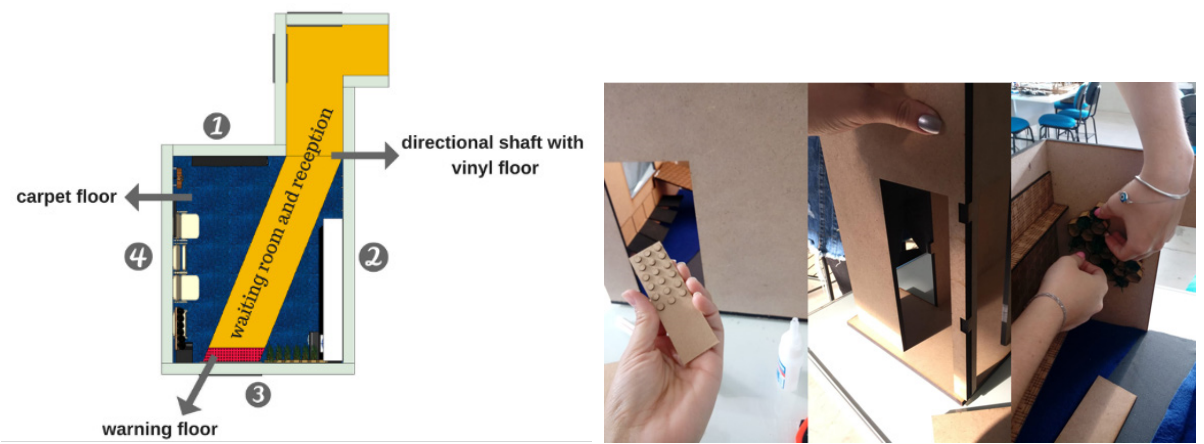

Figure 4. Floor solution and tactile model

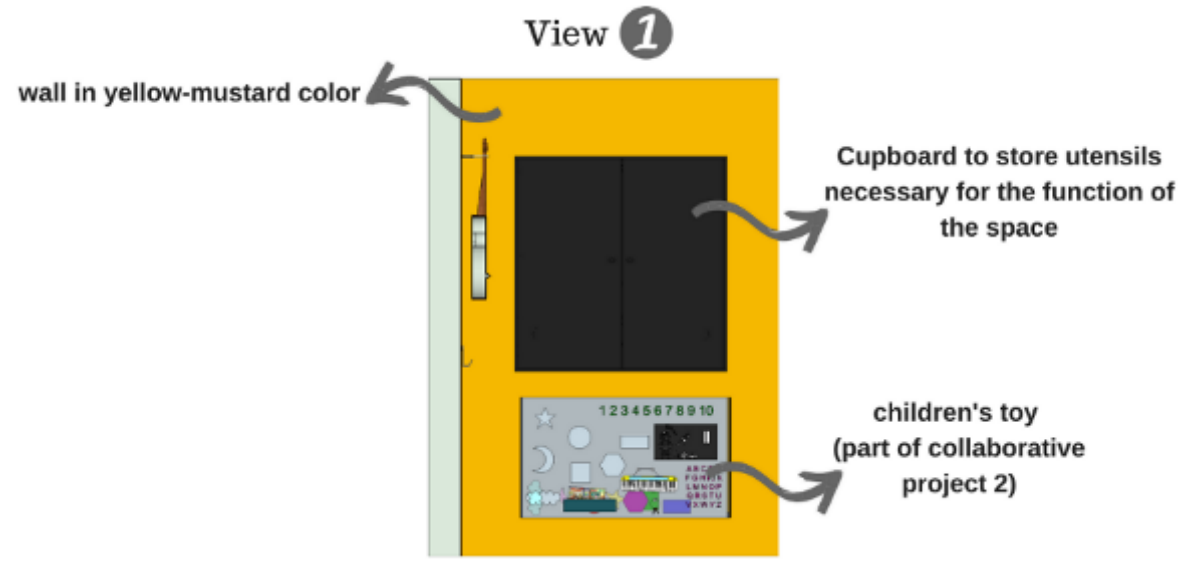

Figure 5. View 1 


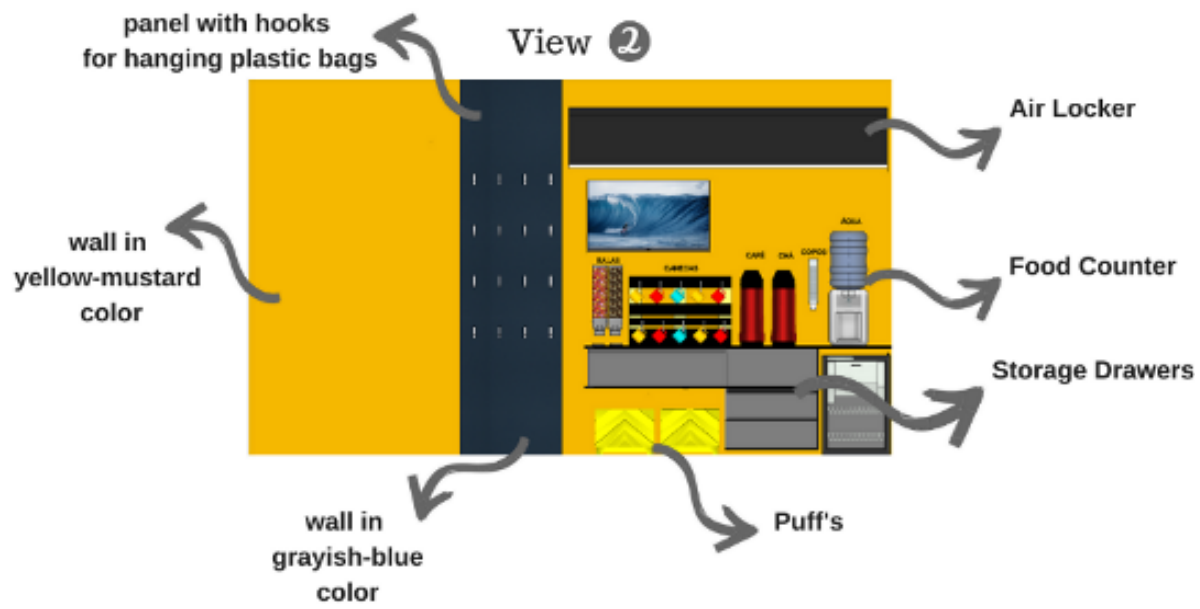

Figure 6. View 2

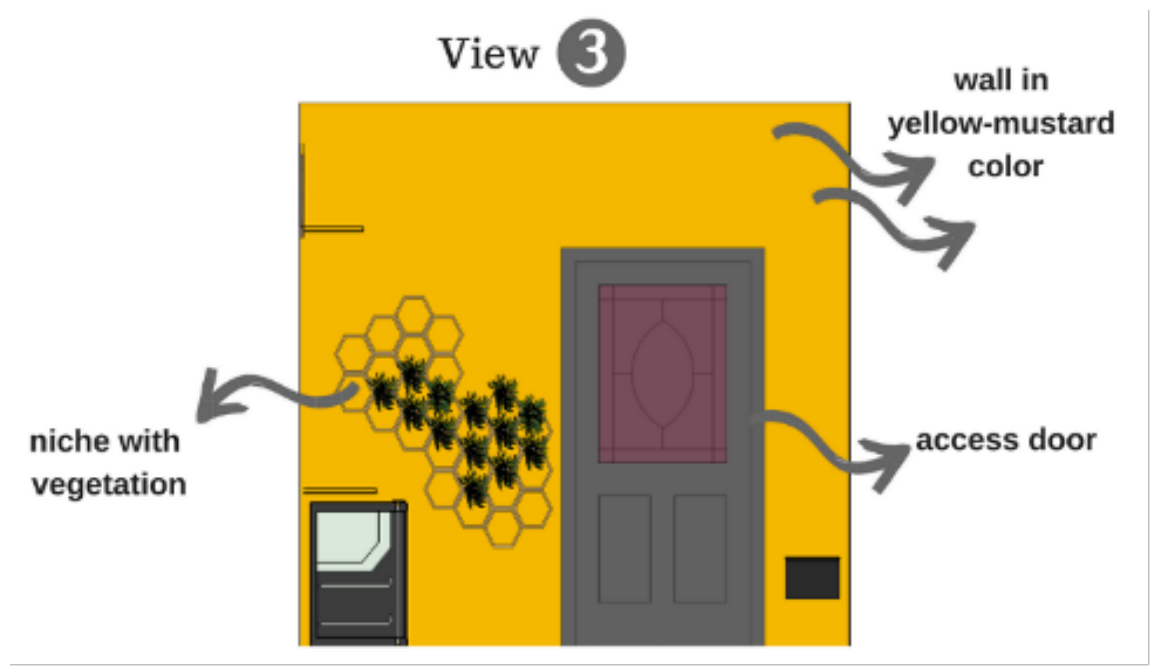

Figure 7. View 3

In view 3 (Figure 7) a niche was elaborated that would be composed of aromatic vegetation, such as rosemary or mint, so that the warmth in the waiting room becomes larger. According to Pallasmaa [15], the architectural space for the B\&VI is understood as the lived space that transcends the geometry and the measurability of the beauty of a facade or the detail of a door, so exploring other skills is of the utmost importance. In this view also the yellow-mustard color was chosen.

For the planning of view 4 (Figure 8) it was necessary to find solutions to improve the exaggerated imminence of light coming from a four-leaf window that occupies the extension of almost every wall, which hinders the mobility of people who are not completely blind. The blocking of the incidence of light will occur through a green panel in which more aromatic vegetation will be placed and by means of a retractable table that will be used at the weekends for the activities of sale of products and during the week will be used as mural as it will be coated with blackboard paper. In view 4 was also planned a high hook to hang a guitar and lower hooks to hang coats. The chairs will also be retractable so that users can sit on the floor and enjoy the carpet floor, thought and elaborated for singing and acoustic activities. There is also a corner desk so that presentation pamphlets for visitors to the headquarters or books in Braille are available to distract users. 


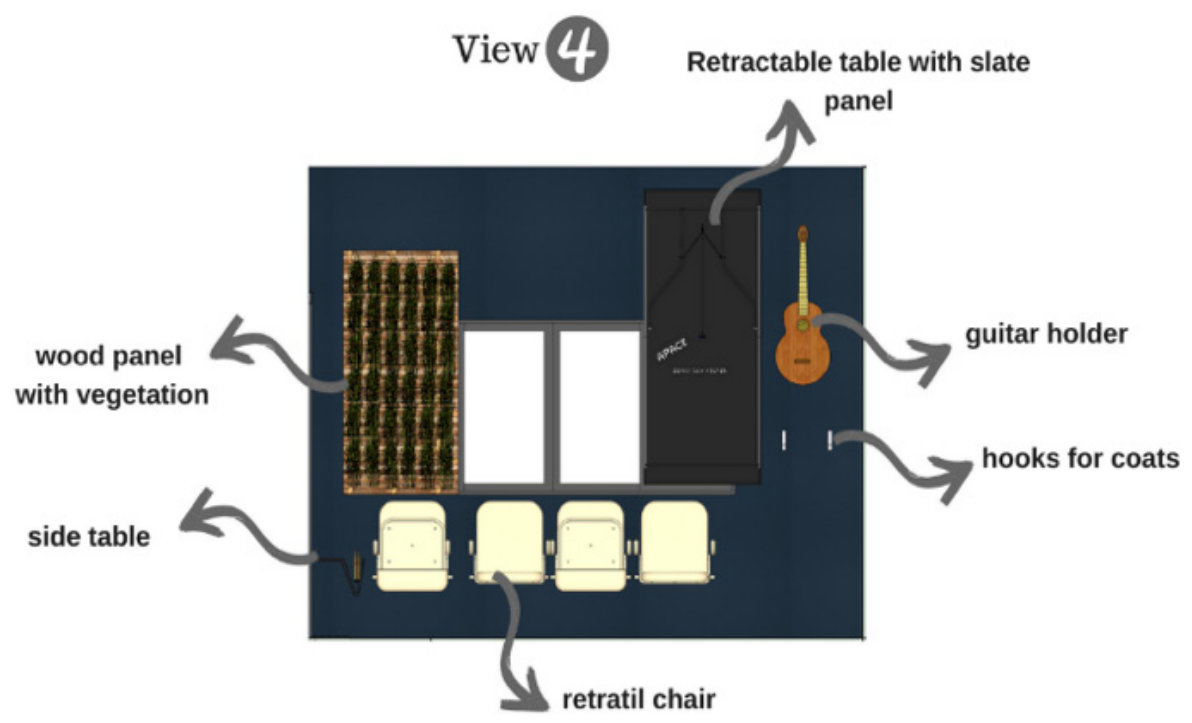

Figure 8. View 4

The Figure 9 represents the third phase of the collaborative project, which was the interaction between the authors and the participants for the use of the tactile model developed in FabLab. The collaboration took place with the same participants from the previous stage. The associates liked the results and were surprised with the care and detailing so that all the requests were reached.

The second issue discussed during the Focus Group activity in the collaborative project with adults was the need to improve the external area, that is, it was debated what attitudes would be essential for this space to become a pleasant environment for relaxation and for children's recreation. The guiding topics (Figure 10), however, were: "What is needed to make the outer area inviting to the members? What is planned for her? Can children play safely? What would be pleasurable to do on the spot? What activities would you like to do in it? What physical elements need to be improved for safe use? ".

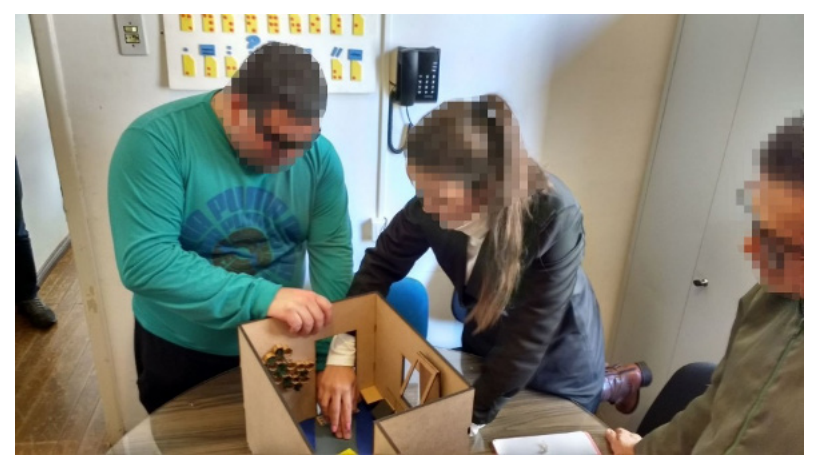

Figure 9. Presentation of the tactile model developed in FabLab

The participants were able to comment on all the guiding topics and the proposal was elaborated according to all the requests and aspirations for the place. It was possible to perceive the commitment of the participants to try not only to think about their own personal desires, but also to look for elements that would satisfy the other associates who were not present in the activity. For the proposal of the external area (Figure 11), it was necessary the composition of floors to better target users, and therefore, the directional axis followed the same pattern of the waiting room. For the rest of the outdoor area the proposal is a rubberized dark floor, ideal for outdoor areas. This attitude is an attempt to standardize the floor of the headquarter, which currently consists of aged dark parquet and a worn outer sidewalk.

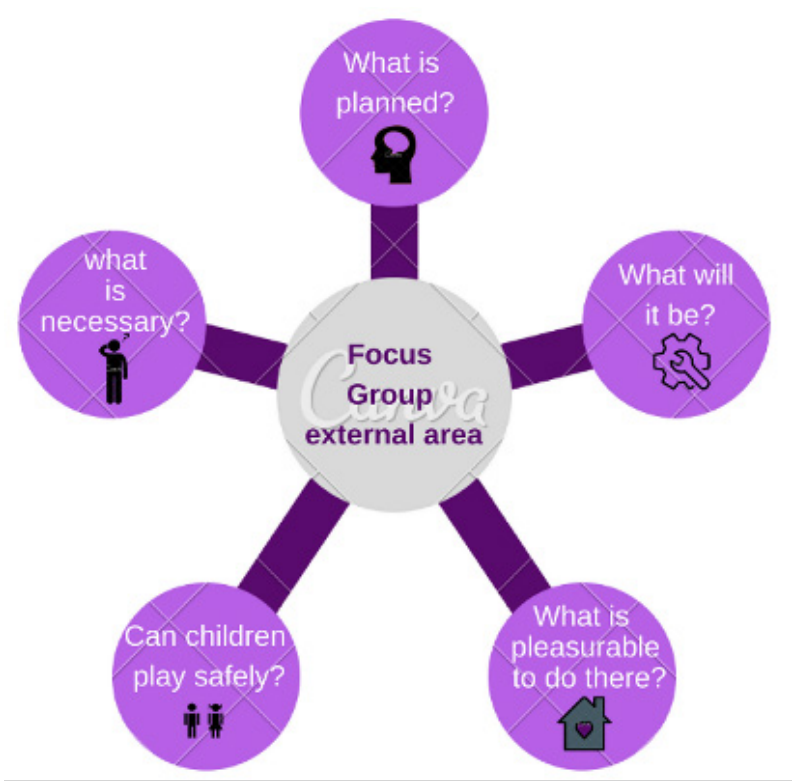

Figure 10. Guiding topics for the external area 


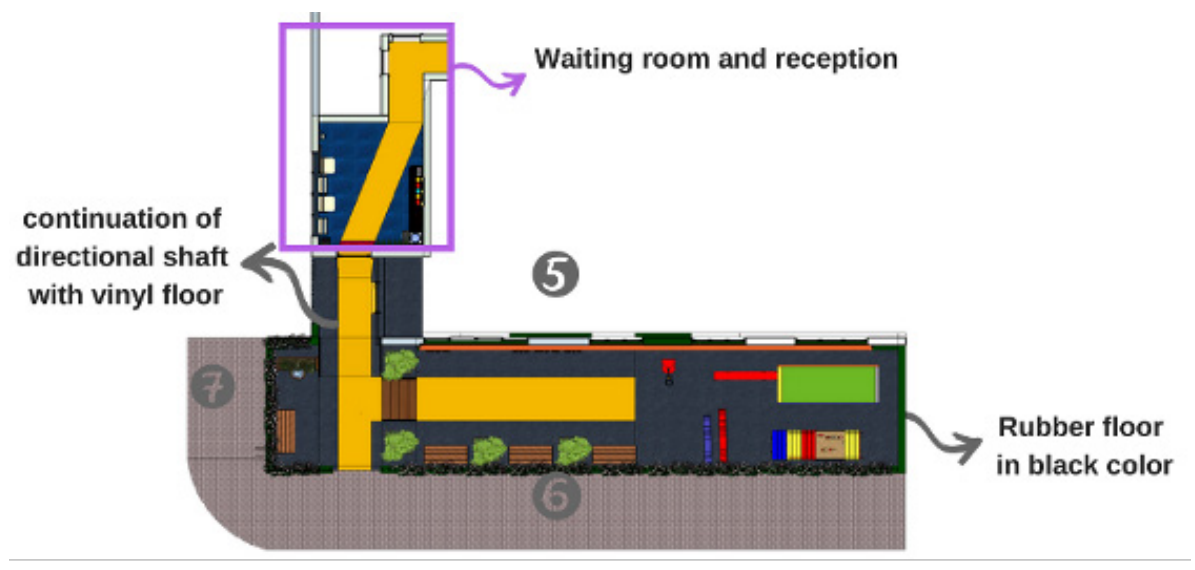

Figure 11. External living area

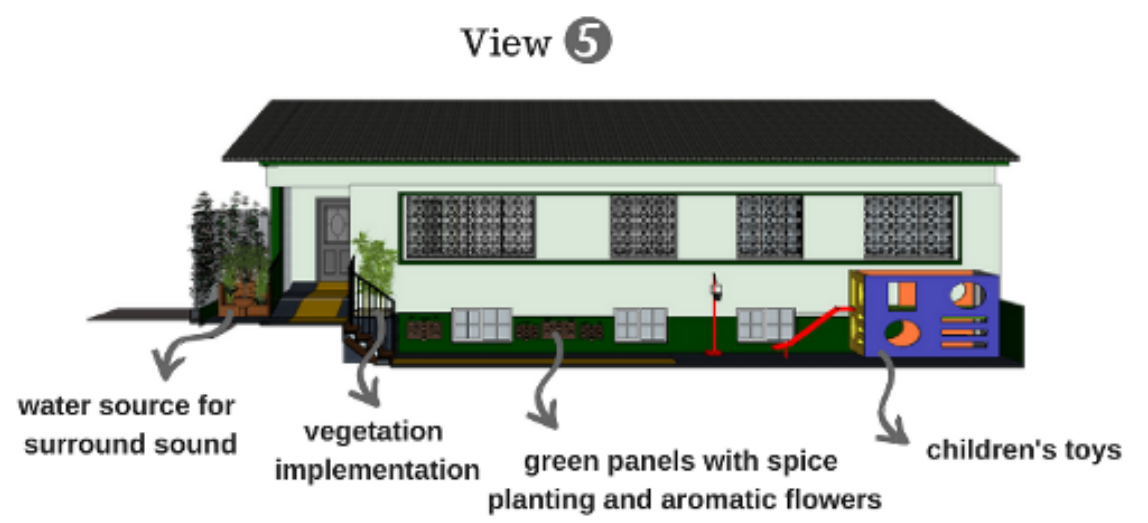

Figure 12. View 5

In view 5 (Figure 12) it is possible to observe the insertion of a water source as a sound element that will bring warmth and warmth to the users. There was also the implementation of green areas, with the placement of flowerbeds and green panels for planting flowers and aromatic leaves. The toys for children's playground were already belonging to the association, was only planes the replacement of the existing slide by the toy of the collaborative project 2 that will be presented next.

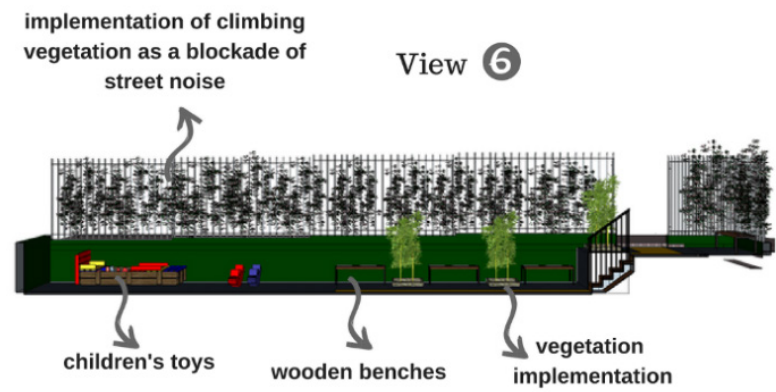

Figure 13. View 6

During the Focus Group participants complained about the noise that the street caused to the environment, as there is no possibility of major interventions, a vegetation system of vines was elaborated for view 6 (Figure 13) so that generate a psychological factor by obstructing the visibility of street passers-by in the interior of the convivial area, and therefore of noise sources.

In view 7 (Figure 14) follows the project with the placement of wooden benches and the continuation of climbing vegetation.

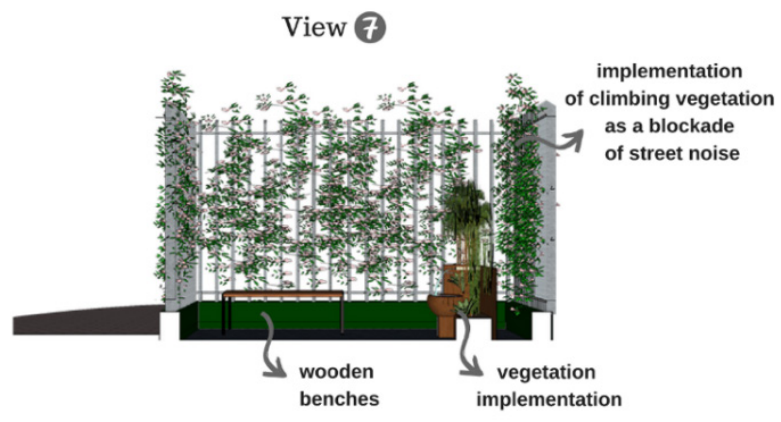

Figure 14. View 7

\subsection{Collaborative Project 2 - With the Children of Association}

Helping children develop all physical and mental areas through planned opportunities to experiment, explore, and play with something is called 'stimulation' or 'early care'. Therefore, the purpose of the collaborative project with 
the children is to create a toy for the waiting room/reception room and the adaptation of a toy, which was created by undergraduate students of architecture and urbanism, to the outside of APACE. Both activities are part of the collaborative project 1 stages, the waiting room/reception project and the project to improve the external part of the association, however, due to its extreme importance and complexity of decisions, it will be considered as a second collaborative project.

Niemann and Jacob [16] explain that there are 3 main areas in which a child develops being physical (body), mental (thinking) and social (interacting with other people), and in each of these areas the child learns new skills. In order for children to learn to walk, for example, first she needs to develop other simple controls of the body and it is mainly through the interest in objects that are close to her that she begins to raise her head to visualize them move your arms and legs so that you get the contact. And at the same time that she develops physical abilities, when she is interested in an object, she also learns to name them, which makes her linguistic and behavioral development also develop. And this learning process leads you to develop control and skills like balance which will be of crucial importance in standing up and walking.

However, when a child has a visual impairment, or lack of vision, this development becomes slower, whereas when a child sees it, he naturally develops some skills that children without vision do not develop. Another important issue that differentiates visually impaired children is the fact that children often learn by copying what they see. That is, they learn to dress, feed themselves, among other activities, and The development of visually impaired children can best be understood by means of an intrinsic analogy to the game 'jenga' (Figure 15), a game of physical ability in which the balance for the pieces of the upper part depends on the correct position of the pieces that are below, that is, a relationship of support. For example, if the child has a problem in learning to hold the head, she will have difficulty learning skills such as sitting or crawling, in which holding the head is important. This is so in the development of visually impaired children who, often because they are not stimulated in a correct way makes, in addition to slow development, a delay situation for the rest of their life, since certain skills are the basis for the social development.

It's important to point out that children with visual impairment are in the first place: children. And as every child has the natural desire to do things that make them feel capable, therefore, as a form of care we chose the participation of those responsible, during the Focus Group, so that the briefing of the toys, in order to offer the maximum of independence and possible use, be careful and cautious. Those responsible were able to make important recommendations at specific points in the activity.

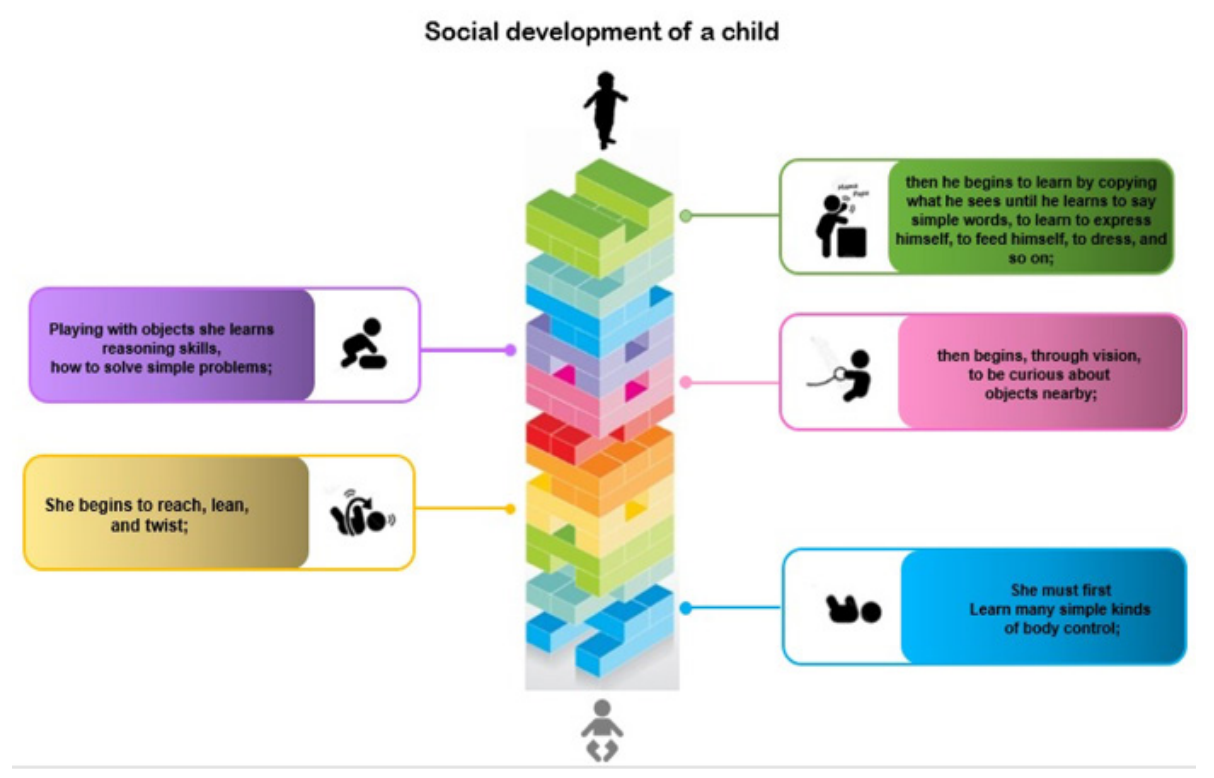

Figure 15. Analogy of the social development of a child to the game jenga. Source: Adapted from Niemann and Jacob [14] 
The collaborative project with children has as a goal (Figure 16) developing recreational elements that explore the main skills necessary for their development and which, at the same time, offer opportunities for interaction between children served by Association and children who eventually attend the association accompanying family members.

The act of playing should not only be a kind of activity that provides fun for the children, but a possibility for them to construct their own perception, more elaborately, about the reality in which it is inserted. Through the games, children create affective bonds, build relationships of friendship and manage to demonstrate their feelings more spontaneously and creatively. The elaboration so that this ludic process, essential for the development of children, happens is even more challenging when the toy aims to pedagogically reach children with visual impairment.

The first elaboration (Figure 17) is a multi-pedagogical toy designed for the inner space of the waiting room/reception that seeks to develop the cognitive part of the child with play of puzzles with geometric figures, toys that have sound elements, letters, numbers and various toys fixed by means of velcro.

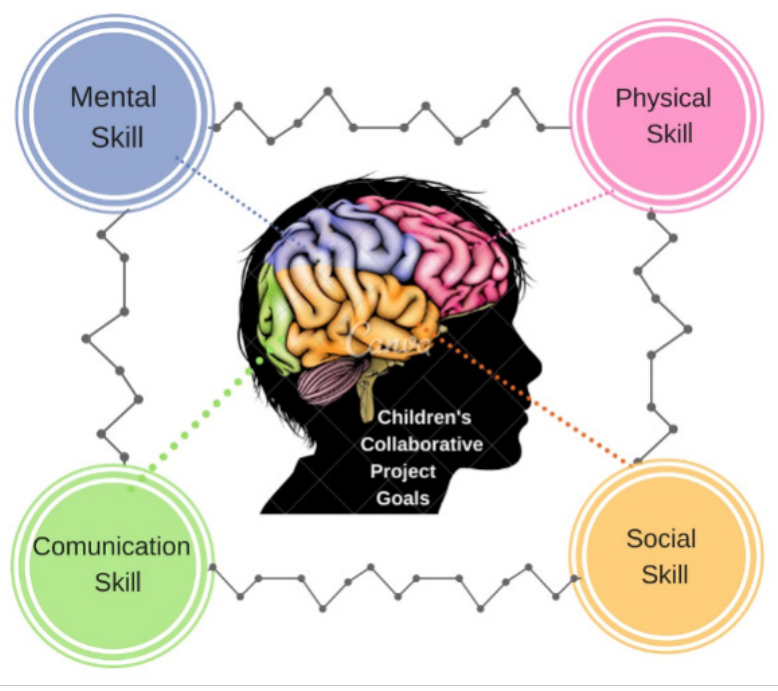

Figure 16. Children collaborative project goals

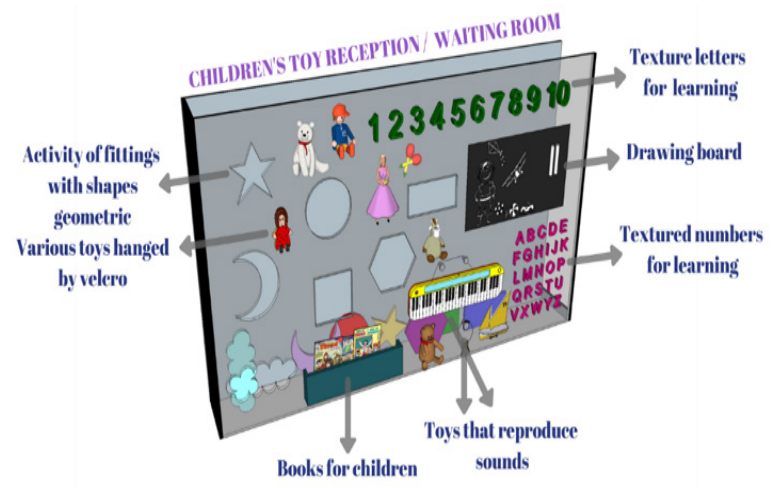

Figure 17. Toy for internal space
The second toy is the result of an activity carried out in the fourth semester of the undergraduation in architecture and urbanism, by the same professor who teaches the discipline of inclusive project of the masters and coordinates the research group, from which a toy was elaborated by means of rapid prototyping product a briefing on a visually impaired child. The toy was elaborated during the discipline and at the end of it could be manufactured in real size for its effective use. The toy fit perfectly with the children's briefing of the Association children, since of all the activities available in playgrounds, the one that the children most emphasized, was that of the slide. At the time, it was also possible for some of the children participating in the activity to experience the toy (Figure 18), together with those responsible, who were able to tell when the toy is dangerous or what are the possibilities for improvement for total independence and safety during use.

The toy will be placed in the outer area of the association within the leisure space with children's furniture and, as a result of all experimentation, will have sound elements so that children are warned of the beginning and end of the steps of the slide as well as directional support of LED lights which will be important for those with different degrees of visual acuity. The toy was tried by a blind child and by one with degree of visual acuity.
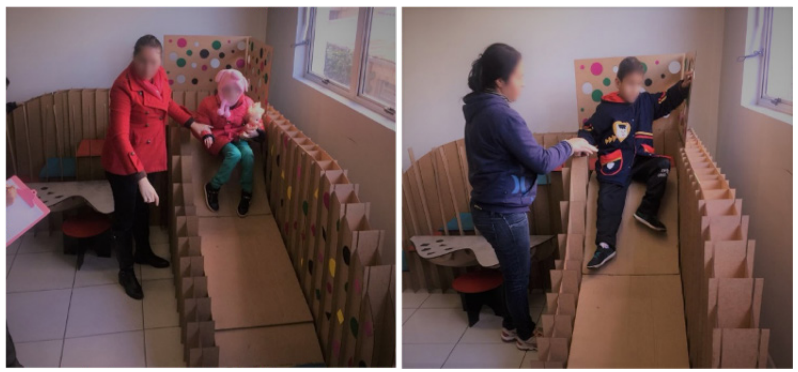

Figure 18. Toy experimentation by visually impaired children

The toy will be placed in the outer area of the association within the leisure space with children's furniture and, as a result of all experimentation, will have sound elements so that children are warned of the beginning and end of the steps of the slide as well as directional support of LED lights which will be important for those with different degrees of visual acuity. The toy was tried by a blind child and by one with degree of visual acuity.

\section{Conclusions}

The main contribution of this article was to present means of representation that promote the effective participation of $\mathrm{B} \& \mathrm{VI}$ in the design process, with the use of digital fabrication. Caixeta and Fabrício (2018, p.3) pointed out that "it is important to study co-design 
methods and instruments to enable their implementation, broadening the understanding among all the multidisciplinary team and reducing time and costs in the design process, to contribute to the quality of the process and of the final product". Establishing a common communication between B\&VI and designers is essential to enable collaboration and interaction, for this to occur the main characteristic of this process, the relationship between the actors involved [7].

The satisfaction that this relationship generates was confirmed by the manifestation of one of the responsible for one of the children involved mentioning that it is the "first time we are listened", as well as by the adult users in the accomplishment in touching the tactile model, more than the plant tactile [7,12], and have something concrete that portrays what they had demanded in the focus group, commenting that "it is sensational" (associate 1), "you managed to capture what we wanted" (associate 2). The participatory project "is more insightful and powerful than the sum of the individual perspective" [17].

Concrete representations such as the tactile model realized in laser cutter, proved adequate to establish a common language of interior architecture design with the adults, just as the prototype of the toy in real scale was propitious for the children assisted by those responsible ones to suggest modifications and design increments.

The Collaborative Project or Co-design methodology under development in this research is broad and has not been developed in an isolated moment or with a view to the development of a single project. The interaction between designers and $\mathrm{B} \& \mathrm{VI}$ and the understanding of the dynamics of use and appropriation of built environments, as well as their design, is a process that is being built through several joint actions over the six years of development of the main project of research.

As shown, the effectiveness and interaction in the joint construction of the projects developed with the Association's B\&VI did not only take place during the development of proposals for the requalification of the reception environments and the external space of the association's current headquarters.

There is a reciprocity of learning between the $\mathrm{B} \& \mathrm{VI}$ and the designers in the co-design process, the moment they emerge in situations not experienced in their daily lives. The B\&VI are faced with instruments of communication and representation of the built environment that are unfamiliar in their daily lives, as well as acting as agents in the design of a project. While they are focused on the primacy of vision and the sensations provided by it, one of the main contributions that the co-design experience reported here offers is the reflection of how projects are conceived without considering all the potential sensations that the environment can allow to those who enjoy it.

Furthermore, the interaction with the B\&VI in the design process ratifies and rectifies what the norms and legislation advocate. An example of this was the opinion of the B\&VI about the need for a tactile directional floor, but rather the warning, color contrast, textures, layout and maintenance of furniture in the same place, which may have mutations in it, however, remaining in the same location.

At the same time, co-design actions demystify preconceived ideas, for example, the idea that it is enough to have signs in Braille and elements with this type of communication for the interaction of the B\&VI and the environment. Focus groups and workshops with members of the Association indicated that less than $20 \%$ read in Braille. The National Federation of the Blind [18] points out that few people with low vision read Braille, preferring to increase fonts and text styles.

The design, representation and teaching of architectural, urbanism, landscaping and interior design is mostly visual $[19,20]$. Actions of this type allow for an understanding of the user and the joint construction and greater assertiveness of design decisions, in a two-way learning process between designers and $\mathrm{B} \& \mathrm{VI}$.

Co-design can help to have a greater understanding of the user and design with him and not just for him [20], thus contributing to an equalization between the knowledge of the designer and the PCDV, also users of the space to be projected. The inclusion of B\&VI in the design process contributes to the designer's education and the reduction of ubiquity in design decisions, bringing them closer to the real needs of users. The participation of the $\mathrm{B} \& \mathrm{VI}$ in the process values their expertise and contributes to a more effective inclusion.

The effectiveness of co-design occurs when participation in the project design and active interaction between designers and actual users is made possible, exchanging expertise, mutually learning and co-creating more assertive alternatives for the project, which will increase the chances of appropriation and belonging to it. Co-design differs from a traditional design process, due to the intensity of interactivity and the complementary nature of the actions, expertise and experiences of each of the agents involved in the process. In this way, it is observed how dependent the need for joint construction and validation of results becomes, in a continuous co-creating - feedback - co-creating - feedback, that is, the co-creation in the design of the project itself and in the methods of interaction and communication and constant feedback of the process by designers and users.

Although co-design is a process of empathy and the abolition of the designer's omnipresence, it maintains some moments of individual actions by designers, for example, in the representation, communication and interpretation of the user's needs and knowledge. It is an exercise in considering the other and feeling the need for the other's expertise, especially when it comes to designing for $\mathrm{B} \& \mathrm{VI}$ and designers do not have the experience of being a B\&VI. The process goes beyond the 
mere consultation of the needs and the restricted validation of the product, for the insertion and collaboration of the user in the process and not only in the project's product.

The main contributions of this research are in the report of the methodology used for interior co-design and landscaping applied to adult B\&VI. Concrete representations such as the tactile model proved to be adequate to establish a common design language for interior architecture. The Collaborative Project with children, on the other hand, was a first experience with little direct influence on the project, requiring further research. It is also suggested that interviews be carried out with occupational therapists to provide greater scalability and expansion of the designers' perception.

It was noticed throughout the study that, at times, the B\&VI participants felt so moved to be able to feel the space and anticipate the new built environment that they failed to point out their perceptions, with the need for constant mediation and encouragement for the continuous sharing of ideas, expertise and desired changes. This is related to the concrete projects themselves, as the expertise and general impressions of mobility, materials, communication and representation are widely debated from the beginning of the project. This fact reinforces the importance of the relationship between the actors involved and the increase in learning.

Co-design provides transformations both in the way the architect designs B\&VI oriented environments, as well as the way in which $\mathrm{B} \& \mathrm{VI}$ manage to become part of the design process. And, at each cycle, new discoveries are made and new paths are opened for the development of a common design language between architects and $\mathrm{B} \& \mathrm{VI}$.

Although the research presented is focused on B\&VI, the definition of a co-design methodology can be scalable to other segments of society, considering that the essence of this method is the people-centered project, regardless of the segment involved. The products and project processes generated or in progress by the practice of co-design experienced in the focus groups, accompanied tours and workshops held with the B\&VI, within the scope of the research group, can, with the systematization of the actions taken and with their continuity, provide important elements for this methodology.

The next steps of the research are to test the toy with the suggested modifications and beyond the use of digital fabrication in its manufacture, to add automation with programming in Arduino, sensors and actuators, which were implanted in smaller scale in the first version of the prototype.

\section{Acknowledgments}

This study was financed in part by the Coordenação de Aperfeiçoamento de Pessoal de Nível Superior-Brasil (CAPES)-Finance Code 001 and National Council for
Scientific and Technological Development (CNPq). We would like to thank the Associação Passofundense de Cegos and the research group Núcleo de Inovação e Tecnologia em Arquitetura e Urbanismo (NITAU-IMED) of the Postgraduate Program in Architecture and Urbanism at Faculdade Meridional (PPGARQ/IMED) for the support received in this research.

\section{REFERENCES}

[1] WHO - World Health Organization, "Blindness and visual impairment",

http://www.who.int/news-room/fact-sheets/detail/blindness -and-visual-impairment. (accessed Feb 28, 2021).

[2] BIANCHIN M., HEYLIGHEN A. "Just design, Design Studies, 54, 2017, pp. 1-22.

[3] ALEXANDER C., SILVERSTEIN M., ANGEL S., ISHIKAWA S., ABRAMS D. "Urbanismo y Participación: El caso de la Universidad de Óregon”. Barcelona: GG, 1978.

[4] CARNEIRO G., BARROS G., ZIBEL C. "Design colaborativo de comportamentos para ambientes interativos". V!RUS, (6). Online available from http://www.nomads.usp.br/virus/virus06/?sec $=4 \&$ item $=8 \&$ lang $=\mathrm{pt}$

[5] CAVALCANTI V. P., ANDRADE A. M. Q., SILVA G. D. A. "Modos de fazer: uma experiência em processo de criação compartilhado e modelo de atuação transdisciplinar na relação entre design e artesanato". V!RUS, (6). http://www.nomads.usp.br/virus/virus06/?sec=4\&item=7\& lang=pt (acessed Feb 28, 2021)

[6] CAIXETA M. C. B. F., FABRiciO M. M. "Métodos e instrumentos de apoio ao codesign no processo de projeto de edifícios,. Ambiente Construído, 18 (1), 2018, pp. 111-131.

[7] MUSSI, A. Q., SILVA, T. L., ZARDO, P., SILVA, J. L., PAZINI, E. Z., FERRI, M., MOREIRA, D. "Welfare increase tools for blind and visually impaired people: inclusive design and tactile model", ARQUITETURAREVISTA (UNISINOS). , v.15, 2019, p.1-14.

http://revistas.unisinos.br/index.php/arquitetura/article/vie w/arq.2019.151.01/60746928

[8] MUSSI, A. Q., SILVA, L. B. O. , LANTELME, E. M. V., CESARO, S. R., DEON, L., RODRIGUES, D. I. , SILVA, T. L.. "Arquitetura inclusiva: experiência de projeto colaborativo, AMBIENTE CONSTRUÍDO (ONLINE), v. 20, 2020, pp. 367-386. DOI:

http://dx.doi.org/10.1590/s1678-86212020000400478

[9] SILVA L. B. O., MUSSI, A. Q. M. "Inclusive Architecture: Digital Technologies, Co-design and Qualification of the Project Process". Journal of Civil Engineering and Architecture, v. 14, 2020, p. 676-684. DOI: $0.17265 / 1934-7359 / 2020.12 .005$

[10] TANUT, W. "A Structural Format to Facilitate User Input for the Co-design of a Cardiac Health Unit," Civil 
Engineering and Architecture, Vol. 8, No. 5, pp. 760 - 770 2020. DOI: $10.13189 /$ cea.2020.080503.

[11] GÜlBAHAR, S., CORDAN, Ö. "The Life Center Unit's Design for Inclusive Schools in Turkey: A Case of Gokkusagi Primary School," Civil Engineering and Architecture, Vol. 6, No. 3, pp. 128 - 135, 2018. DOI: 10.13189/cea.2018.060302.

[12] MUSSI, A.Q., ROMANINI, A., LANTELME, E., MARTINS, M.S. “Arquitetura inclusiva: a planta tátil como instrumento de projeto colaborativo com portadores de deficiência visual". In: Congreso de la Sociedad Iberoamericana de Gráfica Digital, 20, Buenos Aires, 2016. Anais... Buenos Aires, SiGraDI, 2016, 3, pp. 387-393. https://doi.org/10.5151/despro-sigradi2016-714

[13] SPERLING D. M., VANDIER I., SCHEEREN R. "Sentir o espaço: projeto com modelos táteis". In Annals of the Sigradi. São Paulo: Sigradi, 2015.

[14] MORGAN D. L., David L. "Focus Groups as Qualitative Research: planning and research design for focus groups". London: Sage, 1997.
[15] PALlASMAA J. "The Eyes Of The Skin: Architecture And The Senses”. New Delhi: Third Edition, 2012.

[16] NIEMANN S., JACOB N. "Helping Children Who Are Blind. Family and community support for children with vision problems", 2000

[17] SANOFF H. "Special issue on participatory design", Design Studies, 28 (3), 2007, pp. 213-215.

[18] National Federation of the Blind. The Braille literacy crisis in America: facing the Truth. Reversing the Trend, Empowering the Blind, 2009.

[19] HEYLIGHEN, A.; HERSSENS, J. "Designerly Ways of Not Knowing: What Designers Can Learn about Space from People Who are Blind". Journal of Urban Design, [s.1.], v. 19, n. 3, p.317-332, 10 mar. 2014. UK Limited. http://dx.doi.org/10.1080/13574809.2014.890042.

[20] MAGNuSSON, C.; HedVAll, P.; CALTENCO, H. Co-designing together with Persons with Visual Impairments. In: PISSAULOX, E.; VELÁSQUEZ, R. Mobility of Visually Impaired People: Fundamentals and ICT Assistive Technologies. [s.l.] Springer International Publishing, 2018. 